\title{
Conhecimento e práticas científicas na esfera pública: antropologia, gênero e sexualidade
}

DoI

http://dx.doi.org/10.11606/ 2179-0892.ra.2018.145514

\section{Sérgio Carrara, Isadora Lins França e Júlio Assis Simões}

- Universidade do Estado do Rio de Janeiro / Rio de Janeiro, RJ, Brasil;

- Universidade Estadual de Campinas / Campinas, SP, Brasil;

- Universidade de São Paulo / São Paulo, SP, Brasil

、scarrara1@gmail.com, isa.linsf@gmail.com, julio.assis.simoes@gmail.com

RESUMO

Nas últimas décadas, gênero e sexualidade circunscreveram um inovador campo de crescente produção intelectual, tornando-se ao mesmo tempo foco significativo de incidência política para antropólogas e antropólogos no Brasil. Com vistas a iluminar disputas em jogo no contexto brasileiro atual, em que o conhecimento que produzimos vem sendo duramente atacado, revisitaremos alguns documentos de posicionamento público, divulgados pelo Comitê de Gênero e Sexualidade da Associação Brasileira de Antropologia ( $A B A$ ) ao longo dos últimos anos. Propomos uma reflexão sobre o tipo de conhecimento que temos produzido sobre gênero e sexualidade, como ele tem impactado o debate público acerca dessas questões e como tem afetado os modos como nossa própria prática científica vem sendo socialmente percebida e avaliada.
PALAVRAS-CHAVE

Gênero, sexualidade, Antropologia brasileira, prática científica, ideologia 
Nas últimas décadas, gênero e sexualidade circunscreveram um campo de crescente e inovadora produção intelectual na antropologia brasileira. E, como era de se esperar, transformaram-se em foco significativo de incidência política para antropólogas e antropólogos, seja individualmente, seja através da própria Associação Brasileira de Antropologia (ABA) e de seu Comitê de Cênero e Sexualidade. Com vistas a colocar em perspectiva as disputas que estão em jogo no preocupante contexto brasileiro atual, em que o conhecimento que produzimos vem sendo duramente atacado, revisitaremos aqui alguns documentos de posicionamento público, divulgados pelo Comitê de Gênero e Sexualidade da ABA ao longo dos últimos anos. Nossa intenção é propor uma reflexão sobre o tipo de conhecimento que temos produzido em torno de gênero e sexualidade, como ele tem impactado o debate público acerca dessas questões e como tem afetado os modos como nossa própria prática científica vem sendo socialmente percebida e avaliada.

O Comitê de Gênero e Sexualidade formou-se a partir de assessorias que a ABA vem desenvolvendo desde meados dos anos 2000 como resposta a um cenário político em que cresciam a visibilidade e o reconhecimento das demandas e reivindicações colocadas pelos movimentos feministas e LGBT. A criação e as ações do Comitê ilustram o modo de atuação pública da própria Associação que, ao longo de sua existência, tem criado diversas assessorias, comissões e comitês temáticos para acompanhar diferentes agendas relacionadas a seus temas de reflexão e se pronunciar fundamentadamente em momentos políticos cruciais.

O engajamento político tem sido uma marca da antropologia que se faz no Brasil. Isso não é de agora, mas se tornou especialmente visível a partir de finais dos anos 1970, quando o processo de "abertura democrática" instaurado no país implicou, nas palavras de Eunice Durham, uma "politização crescente do nosso universo social" (Durham, 1986: 27), incidindo sobre as ciências de modo geral e, particularmente, sobre a antropologia. Para Durham, na medida em que as populações estudadas pela disciplina ganhavam visibilidade como sujeitos ou atores políticos, organizando movimentos e demandando participação na vida nacional, a própria antropologia se renovava e se revigorava no processo de redemocratização do país. Conforme ela escreveu, há mais de trinta anos:

O sucesso recente da antropologia está certamente vinculado ao fa to de que hoje, essas minorias desprivilegiadas emergem como novos a tores políticos, organizam movimentos e exigem uma participação na vida nacional da qual estiveram secularmente excluídos (Durham, 1986: 18).

Ao mesmo tempo, a antropóloga alertava também que a politização colocava outros desafios à produção de conhecimento. Se, por um lado, o engajamento 
político exigia a incorporação das vivências, sentimentos e conflitos das pessoas pesquisadas e do/a próprio/a antropólogo/a, por outro, também tornava urgente e necessário aprofundar a reflexão sobre esses novos 'sujeitos'/'objetos' de conhecimento e investigação, bem como sobre os conflitos, diversidades e desigualdades na própria relação de pesquisa (Durham, 1986; Machado, 2015).

Dessa perspectiva, o engajamento político não se constitui em entrave ao compromisso básico com o conhecimento, o rigor e a crítica. Ao contrário, além de ter se tornado um imperativo ético, permitiu que praticantes da antropologia tornassem mais refinada a compreensão de seu próprio ofício, problematizando contextos e condições em que seus próprios discursos emergiam e eventualmente entravam em campos conflagrados. A competência específica da antropologia para a coleta e o registro de experiências sociais, sustentada na "comunicação simbólica que supõe e repõe processos básicos responsáveis pela criação de significados e de grupos" (Cardoso, 1986: 103), torna-a especialmente afeita e sensível ao complexo de interações e transações que viabilizam o trabaIho de investigação científica, com evidentes implicações políticas. As pesquisas antropológicas constituem, assim, espaço de intensa troca de ideias, linguagens e preocupações entre diferentes "posições situadas" (Haraway, 1995). Chamar a atenção para isso implica reconhecer o diálogo complexo e multifacetado a partir do qual é produzido um conhecimento que parte do princípio de que deve considerar as interfaces cambiantes entre os saberes situados de pesquisadores e das pessoas e populações em foco, tendo sempre em perspectiva as razões sociais e políticas que o tornam significativo.

Julgamos especialmente importante recuperar essas reflexões neste momento em que antropólogas e antropólogos se veem no centro de um torvelinho que põe em questão as relações entre inserção política e produção de conhecimento. Depois de acompanhar nas últimas duas décadas a consolidação e a expansão do campo de estudos antropológicos, correlativas à crescente autonomização da sexualidade e das identificações e expressões de gênero como domínios centrais de reivindicação e exercício de direitos, deparamo-nos agora com os efeitos decorrentes não apenas dessa maior visibilidade e das transformações sociais relacionadas a mulheres e pessoas LGBT, especialmente no plano da jurisprudência e das políticas públicas, mas também das investidas ou reações que se organizam contra essas mesmas transformações. Somos arrastados para um contexto em que os direitos dos sujeitos políticos com que trabalhamos estão sendo atacados e em que se questiona a própria legitimidade do conhecimento antropológico que temos produzido com eles no campo dos estudos de gênero e sexualidade.

Uma breve avaliação da atuação do Comitê de Gênero e Sexualidade da ABA, através de suas notas, cartas e relatórios da presente década (2010), mostra 
como reagimos a uma sucessão de ataques relacionados a questões de gênero e sexualidade que se desenrolaram desde as mídias até o poder legislativo, ocupando por certos períodos o centro do debate público. Nesses últimos anos, os pronunciamentos públicos da ABA gravitaram em torno de temas como:

- violência contra a mulher, criticando o tratamento dispensado pelas mídias e instituições aos casos de violência sexual, incluindo os episódios de "estupro coletivo", como "forma de humilhação e controle da mulher e de corpos que venham a ser feminizados" (ABA, 2016a)';

- investidas contra direitos sexuais e reprodutivos por parte do Legislativo, criticando iniciativas como o Estatuto do Nascituro e o PL 5069/2013, que visam: restringir a abrangência de atendimento a mulheres vítimas de violência sexual nos hospitais, criminalizar o anúncio de meios abortivos e a mera orientação e instrução de como praticar o aborto mesmo nos casos previstos pela lei. O Comitê enfatizava a autonomia ou autodeterminação das mulheres nas decisões relativas à sua vida reprodutiva (ABA, 2015a, 2015b)

- violência contra pessoas LCBT, denunciando, por exemplo, o assassinato do antropólogo Cleides Antonio Amorim, da UFT (ABA, 2012) ${ }^{3}$ e criticando publicamente o Decreto Legislativo 234/2011 que visa revogar a Resolução do Conselho Federal de Psicologia contrária ao emprego de terapias de reversão sexual - a chamada "cura gay" (ABA, 2013; 2017) ${ }^{4}$. O Comitê enfatizava a urgente necessidade de erradicar no Brasil o preconceito, o ódio e as discriminações baseadas na orientação sexual e identidade de gênero;

- propostas de mudanças da legislação sobre prostituição, criticando a tendência de crescente criminalização das atividades de trabalho sexual e repudiando acusações e ameaças dirigidas a lideranças de movimentos de prostitutas, assim como a pesquisadores e pesquisadoras do tema (ABA, 2016b).

É importante ressaltar que esses posicionamentos se baseiam em elaborações conceituais com lastro empírico acumulado de longa data. Em que pesem nossas divisões internas em relação a teorias e metodologias, tais elaborações refletem procedimentos estruturantes da antropologia como prática científica, que implicam certa tomada de posição a respeito da própria natureza do conhecimento que produzimos. De modo geral, podemos afirmar que o conhecimento antropológico tem relativizado concepções de pessoa que se pretendem fundadas em atributos de sexo, sexualidade e gênero supostamente essenciais, imutáveis e universalmente válidos. Dado o solo empírico e conceitual construído pela disciplina no pós-guerra e os compromissos éticos e políticos por ela assumidos frente às populações que estuda, cabe-nos a tarefa contínua de desnaturalizar taxonomias e práticas classificatórias e tratá-las como produções cultural e historicamente particulares, sujeitas à controvérsia e à transformação.
1 Ver "Nota da Associação Brasileira de Antropologia (ABA) e de seu Comitê de Gênero e Sexualidade sobre os recentes casos de estupro coletivo", maio de 2016

2 Ver "Nota da Associação Brasileira de Antropologia e de seu Comitê de Gênero e Sexualidade sobre o Projeto de Lei no. 5069/2013", outubro de 2015.

3 Ver "Nota e ofícioassassinato do antropólogo Cleides Amorim: mais um dos casos de violência cotidianamente perpetrada há décadas contra gays, lésbicas, bissexuais, travestis, transexuais e transgêneros no Brasil", fevereiro de 2012.

4 Ver "ABA denuncia a 'cura gay' - Nota do Comitê Gênero e Sexualidade encaminhada (25/06/13) ao Conselho Federal de Psicologia (CFP)", junho de 2013, e "Nota de apoio à resolução 01/1999 do Conselho Federal de Psicologia, que estabelece normas de atuação para os psicólogos em relação à questão da Orientação Sexual, vedando explicitamente a participação desses profissionais em eventos e serviços que proponham tratamento e cura das homossexualidades", outubro de 2017 
Ao mesmo tempo em que entende gênero e sexualidade como eixos de ordenação de hierarquias e desigualdades sociais duradouras, a antropologia não tem tratado tais ordenações como campos fixos de relações de poder, mas como terrenos em disputa. Nesse sentido, gênero e sexualidade vêm sendo compreendidos como campo de relação entre sujeitos socialmente constituídos em contextos singulares e como elementos de processos mais amplos de regulação social e exercício de poder. Suas intersecções políticas e culturais têm sido capazes de produzir uma impressionante multiplicidade de expressões e identificações de gênero e uma variedade de combinações entre tais expressões e desejos ou orientação sexual.

Com efeito, gênero e sexualidade surgem também como linguagem para disputas que excedem seus próprios limites (Scott, 1986) e têm historicamente operado como símbolos catalisadores de ansiedades e medos pessoais e sociais que, em princípio, Ihes são estranhos. Ceram-se assim os chamados "pânicos morais" (Weeks, 1981; Rubin, 1984), como o que, entre nós, vem se construindo em torno da pedofilia ou da 'sexualização' de crianças e adolescentes. Talvez seja essa uma boa chave para compreender o que está em jogo atualmente. Assistimos a uma crescente disseminação de pânicos morais, desde a decisão da Presidente Dilma Rousseff de suspender em 2011 o projeto Escola Sem Homofobia após pressão e protestos de parlamentares moralmente conservadores e/ ou vinculados às chamadas bancadas religiosas no Congresso Nacional até as investidas mais recentes que resultaram na eliminação das referências a gênero, diversidade e orientação sexual dos Planos de Educação em todo país em 2015. Já no governo de Michel Temer, em 2016 e 2017, acompanhamos os debates sobre a chamada "Escola sem Partido" e a própria supressão pela Câmara dos Deputados da expressão "perspectiva de gênero" do documento que orienta a competência do Ministério das Mulheres, da Igualdade Racial e dos Direitos Humanos (atualmente renomeado para Ministério dos Direitos Humanos). Certa ansiedade paranoica, amplificada pelas redes sociais, alastra-se em direção à proibição de expressões artísticas e a manifestações contra intelectuais, como aconteceu com a exposição Queer Museu, em Porto Alegre, e com a vinda da professora Judith Butler ao Brasil, em 2017. Estigmatiza-se a chamada 'ideologia de gênero' como um suposto plano para 'sexualizar', corromper ou perverter crianças inocentes e destruir 'a' família. Tal plano teria sido deliberado e concertado por movimentos sociais e seus aliados na academia, em instituições da sociedade civil e até no próprio governo.

As manifestações públicas da $A B A$, voltadas mais claramente à incidência política, foram acompanhadas do esforço-realizado através da organização de fóruns, GTs e seminários acadêmicos, e da publicação dos seus resultados em periódicos científicos de circulação nacional - na direção do amadureci- 
mento da reflexão sobre nossa própria prática nesse campo empírico e sobre os contextos políticos em que nos embrenhamos. Como resultado, produziram-se balanços sobre a reflexão antropológica em temas centrais para o campo dos estudos de gênero e sexualidade no Brasil $^{5}$ e, mais recentemente, promoveram-se debates sobre 'conservadorismos', 'fundamentalismos' e 'violências'. Com a emergência mais recente da luta contra a disseminação da suposta 'ideologia de gênero', que mobiliza particularmente lideranças cristãs, estreita-se também o diálogo com antropólogos e antropólogas que atuam no campo de estudos da religião.

Sobre esse último ponto, vale tecer algumas considerações adicionais. A ABA divulgou notas e pronunciamentos críticos nos episódios em que a categoria 'ideologia de gênero' tornou-se pública. Apesar disso, é em torno dela que se constituem hoje talvez os mais espinhosos desafios à prática profissional de antropólogos e antropólogas, bem como de demais pesquisadores e pesquisadoras atuantes no campo de estudos de gênero e sexualidade, visto que o próprio conhecimento antropológico passa a ser acusado de 'ideologia'. Cabe ressaltar que, nesse campo de estudos, o que se figura propriamente como espécie de ideologia, ou ao menos como ideário, em flagrante contradição com o que os dados empíricos têm revelado desde (pelo menos) os pioneiros estudos que a antropóloga norte-americana Margaret Mead (1935) conduziu ainda na primeira metade do século passado, são exatamente as ideias sustentadas pelos que hoje combatem a 'ideologia de gênero'. Entre as principais: a de que haveria modos universais das pessoas se relacionarem como homens e mulheres, a de que tais modos são derivados do aparato anátomo-fisiológico humano e objetivam a reprodução biológica e, finalmente, a de que relações não-heterossexuais devem ser tratadas, no campo científico, como anomalias ou doenças.

Do nosso ponto de vista (e sem revisar aqui posições que vêm sendo sedimentadas há pelo menos meio século), essa lamentável situação merece uma reação baseada num duplo argumento, que pode parecer contraditório aos não familiarizados com o campo da antropologia ou dos estudos de gênero e sexualidade. É preciso que encontremos um ponto de equilíbrio entre, de um lado, a afirmação de que o conhecimento que produzimos é necessariamente situado - política e epistemologicamente-e, portanto, jamais 'neutro'; e, de outro, a defesa da autonomia (relativa por certo) do campo científico e das convenções que o regem. Ou seja, é fundamental que se esclareça que, sempre politicamente implicado, o que produzimos é conhecimento e não 'ideologia' ou algum tipo de 'opinião' que possa prescindir do rigor lógico, conceitual e metodológico que aplicamos às pesquisas que realizamos. É nesse campo que a discussão deve ser travada e não no das paixões morais, onde se instalou o espantalho do predador sexual, do pedófilo, que divulgaria 'ideologias', ou seja, falsas teorias científicas nas escolas brasileiras
5 Em 2014, os Cadernos Pagu publicaram o "Dossiê Antropologia, Cênero e Sexualidade no Brasil: Balanço e Perspectivas", resultado de atividades organizadas pelo Comitê de Gênero e Sexualidade da ABA, com balanços críticos da produção antropológica sobre gênero e sexualidade no Brasil em seus vários campos temáticos (Piscitelli, 2014). Em 2017, o periódico publicou o "Dossiê: Conservadorismo, Direitos, Moralidades e Violência", fruto, entre outros, de iniciativas relacionadas ao Comitê de Cênero e Sexualidade da ABA (Facchini e Sívori, 2017). Em fevereiro de 2016, a ABA publicou em seu informativo especial um esforço conjunto de produzir diagnósticos que versavam também sobre a diversidade sexual e de gênero, família e prostituição (ABA, 2016c). 
apenas para satisfazer sua luxúria sobre crianças e adolescentes incautos.

Em suma, para responder a esse desafio, talvez seja pouco argumentar que não existe neutralidade científica do ponto de vista dos direitos humanos e da cidadania. É preciso insistir na especificidade da prática científica que perseguimos. É preciso lembrar que não há professor/a e/ou pesquisador/a neutro/a do ponto de vista das concepções que mantém sobre educação e sobre o mundo natural e humano, porque nas ciências contemporâneas trabalhamos com diferentes teorias ou paradigmas, sempre provisórios, incompletos e muitas vezes em conflito. No campo científico, discutimos teorias, conceitos e resultados de investigações metodologicamente controladas. As ideologias, nós as estudamos (descrevemos, interpretamos ou explicamos) como mais uma manifestação do humano. Mantemos, assim, uma vigilância epistemológica constante no sentido de controlar, ou ao menos deixar visíveis, as possíveis interferências entre as teorias ou paradigmas científicos com que operamos e esses outros ideários a que chamamos de 'crenças religiosas', 'opiniões políticas', 'ideologias', 'moralidades'. Como se vê, não somos absolutamente neutros quando se trata da possibilidade de crenças ou concepções religiosas pautarem ou, pior, substituírem os paradigmas ou as teorias científicas com que trabalhamos. Dito de outro modo, há mais de dois séculos acendemos nossas velas a ideários dessacralizados, contestáveis, ancorados em certa empiria e em certa racionalidade. A autonomia do campo científico, mesmo que seja como valor, deve, portanto, continuar a ser defendida.

A falácia da 'ideologia de gênero' responde a uma estratégia política de conferir o estatuto de crença religiosa ou de posicionamento moral particular ao conhecimento científico, produzido a partir de seus singulares métodos. É o que acontece quando, baseados em suas convicções religiosas e tentando impô-las a toda a sociedade, os atuais partidários da 'ideologia de gênero' dão tal rótulo a todo o conhecimento que se produziu nos últimos cem anos em torno do gênero como conceito e princípio de estruturação de relações de poder historicamente específicas e culturalmente diversas. Ou quando defendem como universais, naturais e eternos, seja o binarismo e a complementaridade entre os gêneros, seja a hierarquia entre as diferentes orientações sexuais, em cujos termos a heterossexualidade teria, por exemplo, maior valor social que a homossexualidade. Somos, assim, levados inexoravelmente à ideia de que alguns tipos de pessoas merecem menos respeito social e, portanto, um acesso mais limitado a direitos do que outras. Isso é que, no nosso campo dos estudos, vem sendo tratado como uma ideologia de gênero, sem aspas. E a ela chamamos comumente heteronormatividade.

Trata-se, como se vê, de mal disfarçada estratégia de inversão pela qual se acusa o conhecimento de ser 'ideológico' apenas para impor a todos uma única 
e bem conhecida ideologia, cujos fundamentos se encontram na moralidade cristã! Diante dessa estratégia, mesmo aderindo a um "positivismo (apenas) estratégico", precisamos defender a legitimidade da prática científica e o caráter particular do conhecimento e da reflexão que produzimos. Precisamos defender igualmente a preeminência que esse tipo de conhecimento deve ter na orientação da política de educação e de outras políticas públicas que terão impacto na garantia dos direitos fundamentais de mulheres e de pessoas LCBT, tais como o direito à vida, à igualdade, à dignidade e à segurança. E se nosso conhecimento deve ocupar esse importante lugar é justamente por não sermos e não podermos ser simplesmente 'ideólogos'.

Ainda, é preciso lembrar que por outros flancos a autoridade profissional da antropologia e de nossa associação na esfera pública também tem sido atacada. Negam-se nossa competência e autoridade específica para produção de laudos sobre grupos étnicos e seus territórios. Há a tentativa de criminalização da prática antropológica, estendendo-se o movimento que busca criminalizar os que têm sido nossos sujeitos de pesquisa, como forma de fragilizá-los ainda mais. Aqui e ali, as populações com que trabalhamos têm sido submetidas à violência e à intolerância de diferentes grupos com diversos interesses e relações com o governo - isso quando não são mesmo atores relacionados diretamente ao governo os perpetradores dessa violência. Não é de se surpreender que, dado nosso comprometimento político com tais sujeitos, nossa competência científica própria esteja colocada em xeque.

Como uma das mais antigas associações científicas do país, a ABA deve se levantar contra o que está acontecendo. E entre nós, praticantes da antropologia, da ciência política e da sociologia, é preciso estreitar o debate, pensar convergências e solidariedades. $O$ tempo urge.

Sérgio Carrara é professor do Departamento de Políticas e Instituições de Saúde do Instituto de Medicina Social da Universidade do Estado do Rio de Janeiro/ UER]. É pesquisador do Centro Latino Americano em Sexualidade e Direitos Humanos e coordenador do Comitê de Gênero e Sexualidade da Associação Brasileira de Antropologia.

Isadora Lins França é professora do Departamento de Antropologia do Instituto de Filosofia e Ciências Humanas da Unicamp e pesquisadora colaboradora do Núcleo de Estudos de Cênero Pagu/Unicamp. É também vice-coordenadora do Comitê de Gênero e Sexualidade da Associação Brasileira de Antropologia. 
Júlio Assis Simões é professor do Departamento de Antropologia da Faculdade de Filosofia, Letras e Ciências Humanas da USP e coordenador do NUMASNúcleo de Estudos dos Marcadores Sociais da Diferença. É membro do Comitê de Gênero e Sexualidade da Associação Brasileira de Antropologia.

\section{REFERÊNCIAS BIBLIOCRÁFICAS}

CARDOSO, Ruth C. L.

1986 "Aventuras de antropólogos em campo ou como escapar das armadilhas do método". In CARDOSO, R. (org.). A aventura antropológica: teoria e pesquisa. Rio de Janeiro, Paz e Terra. pp. 95-105.

DURHAM, Eunice R.

1986 "A pesquisa antropológica com populações urbanas: problemas e perspectivas". In CARDOSO, R. (org.). A aventura antropológica: teoria e pesquisa. Rio de Janeiro, Paz e Terra. pp.17-37.

FACCHINI, Regina e SÍVORI, Horácio

2017 "Conservadorismo, direitos, moralidades e violência: situando um conjunto de reflexões a partir da Antropologia". Cadernos Pagu, Campinas, n. 50, e175000.

HARAWAY, Donna

1995 "Saberes localizados: a questão da ciência para o feminismo e o privilégio da perspectiva parcial". Cadernos Pagu, Campinas, n. 5: 7-41.

MACHADO, Lia Zanotta

2015 "Inserção política: incômodo ou marca da antropologia. Gênero e Sexualidade, um caso particular?" Comunicação apresentada na sessão "Antropologia e questões de gênero e sexualidade: mais além da observação participante". Seminário ABA + 60-Os antropólogos e a antropologia na esfera pública: cenários contemporâneos e políticas para o futuro, Brasília, ABA, UnB.

MEAD, Margaret

1935 Sex and Temperament in Three Primitive Societies. Nova York, W. Morrow \& Company. 
PISCITELLI, Adriana

2014 "Apresentação". Cadernos Pagu, Campinas, n. 42: 7-12.

RUBIN, Gayle

1984 "Thinking Sex: Notes for a Radical Theory of the Politics of Sexuality". In VANCE, C. (org.). Pleasure and Danger.

Nova York, Routledge/Kegan Paul. pp 267-319.

SCOTT, Joan

1986 "Cender: A Useful Category of Historical Analysis". The American Historical Review, Bloomington, v. 91, n. 05: 1053-1075.

WEEKS, Jeffrey

1981 Sex, Politics and Society: The Regulation of Sexuality since 1800. Londres, Longman.

\section{DOCUMENTOS CITADOS}

Associação Brasileira de Antropologia (ABA)

2017 "Nota de apoio à resolução 01/1999 do Conselho Federal de Psicologia, que estabelece normas de atuação para os psicólogos em relação à questão da Orientação Sexual, vedando explicitamente a participação desses profissionais em eventos e serviços que proponham tratamento e cura das homossexualidades".

2016a "Nota da Associação Brasileira de Antropologia (ABA) e de seu Comitê de Gênero e Sexualidade sobre os recentes casos de estupro coletivo".

2016b "Nota em apoio aos direitos das prostitutas, a suas reivindicações sobre o reconhecimento de sua ocupação como trabalho e sobre o combate ao estigma social que historicamente têm sofrido".

2016c "Balanços parciais a partir de perspectivas antropológicas - Informativo especial - conjuntura n 01/2016".

2015a "Nota a respeito do Projeto de Lei n. 6.583/2013, que propõe a criação do Estatuto da Família".

2015b "Nota da Associação Brasileira de Antropologia e de seu Comitê de Cênero e Sexualidade sobre o Projeto de Lei no. 5069/2013".

2015c "Nota sobre a supressão de "gênero" e "orientação sexual" nos planos municipais, estaduais e nacional de educação".

2013 "ABA denuncia a "cura gay" - Nota do Comitê Cênero e Sexualidade encaminhada (25/06/13) ao Conselho Federal de Psicologia (CFP)". 
Dossı|̂́ | Sérgio Carrara, Isadora Lins França e Júlio Assis Simões | Conhecimento

e práticas científicas na esfera pública: antropologia, gênero e sexualidade

2012 "Nota e ofício - assassinato do antropólogo Cleides Amorim: mais um dos casos de violência cotidianamente perpetrada há décadas contra gays, lésbicas, bissexuais, travestis, transexuais e transgêneros no Brasil". 


\section{ABSTRACT}

In the last decades, gender and sexuality have circumscribed an innovative field of increasing intellectual production, becoming at the same time a significant focus of political action for anthropologists in Brazil. In order to put into perspective the disputes that are at stake in the current Brazilian context-in which the knowledge we produce has been severely attacked - we will revisit some documents of public positioning, published by the Cender and Sexuality Committee of the Brazilian Association of Anthropology ( $A B A$ ) over the last few years. We propose a reflection on the kind of knowledge we have produced about gender and sexuality, how it has impacted the public debate about these issues and how it has affected the ways in which our own scientific practice has been socially perceived and evaluated.

\section{KEYWORDS}

Cender, Sexuality, Brazilian Anthropology, Scientific Practice, Ideology

Recebido em 18 de fevereiro de 2018. Aceito em 10 de março de 2018. 